\section{Encefalopatía crónica no progresiva de la infancia (parálisis cerebral infantil)}

\section{Chronic non-progressive encephalopathy of childhood (infantile cerebral palsy)}

\section{Sr. Editor.}

La parálisis cerebral infantil ( PCI) se define como el conjunto de trastornos neurológicos que afectan el tono, postura y movimiento de carácter no progresivo, originada por daño en el cerebro en desarrollo ${ }^{1}$.

Se destaca entre las características la deficiencia neuro-psicomotora que dificulta la realización de actividades de la vida diaria (ADV), este compromiso motor se agrava en presencia de condiciones asociadas como epilepsia, complicaciones respiratorias, reflujo gastroesofágico, sialorrea, trastornos de deglución, discapacidad intelectual, discapacidad visual y auditiva; dificultando la ejecución de higiene bucal debido a los movimientos involuntarios de los miembros superiores, en muchos casos falta de entendimiento y cooperación, requiriendo la participación de un cuidador responsable para realizar la higiene adecuada, con un impacto negativo en la salud bucal de la persona asistida ${ }^{2}$.

Dentro de la población de las personas con discapacidad que son asistidas por los especialistas en odontología para pacientes con necesidades especiales, las personas con encefalopatía crónica no progresiva de la infancia presentan gran número de factores predisponentes para desarrollar dolencias bucales, alta prevalencia de caries, bruxismo, respiración bucal, babeo, atresia de maxila, maloclusión, gingivitis, periodontopatía, alteraciones del flujo y composición salivar, cálculo dental y alteraciones en la microbiota bucal; además, la ingesta de anticonvulsivantes puede producir aumento gingival ${ }^{3,4}$.

Existen pocos profesionales especialistas en la atención de estos pacientes, muchas de las deficiencias en esta área tienen su origen en la formación profesional en pre y pos grado. Las consultas odontológicas deben ser planificadas reconociendo las necesidades de cada paciente y deben estar basadas en promoción de salud: acciones educativas, preventivas y rehabilitadoras.

\section{Carta al Editor}

\author{
Mylene Quintela Lucca 1,a, Edith Mercedes Falconí \\ Salazar ${ }^{2, b}$, Gloria Maria Pimenta Cabral ${ }^{3, c}$ \\ ${ }^{1}$ Universidade Vale do Rio Doce UNIVALE, Minas Gerais, \\ Brasil. \\ ${ }^{2}$ Asociación Sociedad Peruana de Odonto Estomatología \\ de Pacientes Especiales (ASPODES), Lima, Perú. \\ ${ }^{3}$ Centro Universitário UNIESP, Paraíba, Brasil. \\ a Doctora en Odontología/Odontopediatría. \\ ${ }^{\mathrm{b}}$ Especialista en Estomatología para Pacientes Especiales. \\ ' Doctora en Odontopediatría.
}

\section{Correspondencia:}

Mylene Quintela Lucca: mylene.lucca@univale.br

Governador Valadares, Minas Gerais, Brasil.

ORCID : 0000-0002-2146-693X

\section{Coautores:}

Edith Mercedes Falconí Salazar: litafalconi@gmail.com ORCID: 0000-0003-1271-3887

Gloria Maria Pimenta Cabral: gloriapimenta2@hotmail.com ORCID: 0000-0003-0104-1448

Conflicto de intereses: Los autores declaran no tener conflicto de intereses.

\section{Recibido: 11/01/21}

Aprobado: 15/01/21

Publicado: 01/04/21 

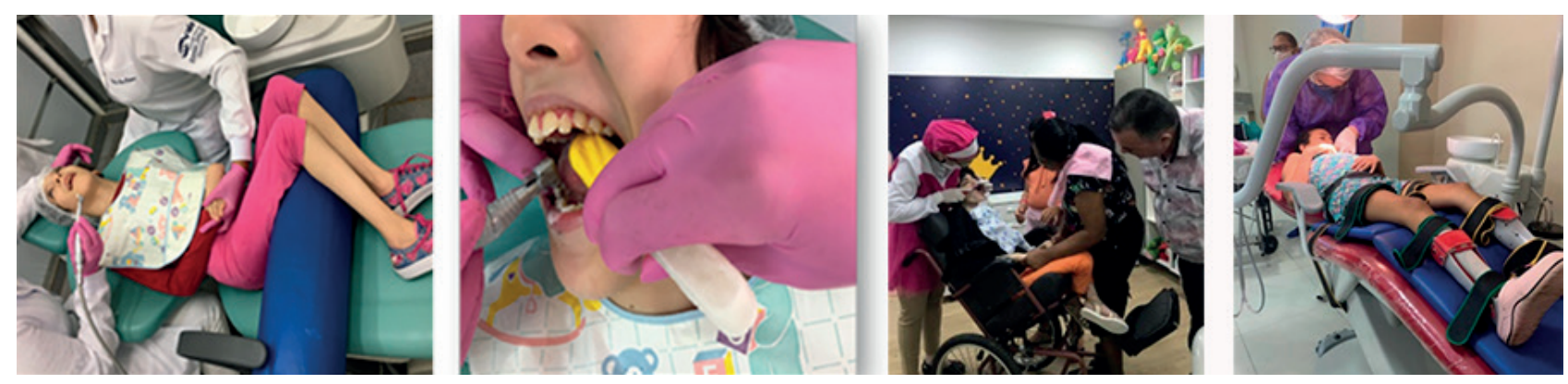

Figura. Estabilizadores y abrebocas utilizados en la atención de pacientes con $\mathrm{PCl}$.

Fuente: PAOPE/UNIVALE.

Para el manejo del paciente en la consulta odontológica se debe considerar ${ }^{4}$ :

- Romper barreras relacionadas a la locomoción, estabilizar movimientos en el sillón odontológico estabilizando la posición del paciente para el tratamiento odontológico (Figura), control de convulsiones, espasmos y alteraciones de tono muscular desencadenadas por estímulos inherentes del tratamiento odontológico: sonoros, gustativos, táctiles, visuales, etc. Debemos inhibir reflejos primitivos como mordida y vómitos.

- Mejorar la habilidad de comprensión, tener adecuada comunicación con nuestro paciente; comunicación alternativa, mediante el uso de fotografías, pictogramas, tableros de comunicación, modelos, filmes, etc.

- Trabajar en equipo y garantizar el apoyo y orientación adecuadas a los familiares y/o cuidadores.

De esta forma se hace necesario la divulgación de información que pueda orientar a la comunidad académica, a los cuidadores y responsables y a los propios pacientes sobre formas de prevenir y controlar la incidencia de esas dolencias odontológicas en las personas con encefalopatía crónica no progresiva (PCI).

\section{Referencias bibliográficas}

1. Arguelles PP. Parálisis cerebral infantil. Madrid: Asociación Española de Pediatría; 2008.

2. Palisano RJ, Chiarello LA, Avery L, et al. Track Study Team (2020) Self-Care Trajectories and Reference Percentiles for Children with Cerebral Palsy. Phys Occup Ther Pediatr. 2020;40(1):62-78. DOI: $10.1080 / 01942638.2019 .1642288$

3. Matsui MY, Ferraz MJPC, Gomes MF, Hiraoka CM. Alteraçôes sialoquímicas e sialométricas de pacientes com paralisia cerebral: uma revisão de literatura. Rev. CEFAC [Internet]. 2011 Feb [citado el 20 de febrero de 2021]; 13(1): 159-164. Disponible en: http://www.scielo.br/scielo.php?script=sci_arttext\&pi$\mathrm{d}=$ S1516-18462011000100019\&lng=en

4. Haddad AS. Odontologia para pacientes com necessidades especiais. São Paulo: Ed Santos; 2007. 